\title{
Immature Eosinophil Count
}

National Cancer Institute

\section{Source}

National Cancer Institute. Immature Eosinophil Count. NCI Thesaurus. Code C96673.

The determination of the amount of immature eosinophils present in a sample. 